\title{
MPPT Control System for PV Generation System with
}

\section{Mismatched Modules}

\author{
Chengyang Huang ${ }^{1}$, Kazutaka Itako ${ }^{1}$, Takeaki Mori ${ }^{1}$ and Qiang $\mathrm{Ge}^{2}$ \\ 1. Department of Electrical and Electronic Engineering, Kanagawa Institute of Technology, Kanagawa 243-0292, Japan \\ 2. Department of Energy and Power Engineering, Yangzhou University, Yangzhou 225127, China
}

Received: September 26, 2014 / Accepted: November 05, 2014 / Published: January 31, 2015.

\begin{abstract}
Nowadays, in a household PV (photovoltaic) generation system, it is generally connecting PV modules in series and then output to the power-conditioner. However, when PV modules are mismatched, it will lead to a wrong MPPT (maximum power point tracking) to all modules and a power decreasing of the whole system. Aiming at this problem, this paper presents the idea which improves the MPPT without changing the conventional power-conditioner, by adding a Buck type DC-DC (direct current) converter behind each module. Simulations of PSIM (power simulation) and experiments are taken to prove this theory. The result shows that, by this idea, the generated power of the conventional PV generation system can be greatly increased under the condition of mismatch.
\end{abstract}

Key words: PV generation system, MPPT, Buck converter, mismatched modules.

\section{Introduction}

Nowadays, in a household PV (photovoltaic) generation system, it is generally connecting PV modules in series and then output a power-conditioner. The power-conditioners which have been widely used in some developed countries generally consist of DC-DC (direct current) converter and inverter. In order to execute PV modules in MPP (maximum power point), the DC-DC converter in power-conditioner has the function of MPPT (maximum power point tracking). $\mathrm{DC}$ is converted into AC (alternating current) in inverter and then connecting the output to the grid or an AC load. But, under the condition of mismatch (modules of different output power, shadows, dirtiness, etc.), this structure of system can led to the problem of mismatch losses [1-3].

The problem has been discussed frequently and some new ideas of solar power system have been proposed. One of the most popular theories is that executing MPPT control to each PV module

Corresponding author: Kazutaka Itako, professor, Dr. Eng., research field: power electronics. E-mail: itako@ele.kanagawa-it.ac.jp. respectively, and then outputting to the inverter. But it is difficult to achieve this idea in some countries (such as Europe, Japan) in which PV generation system has already been widely used. In order to realize this idea, the conventional power-conditioner which has both DC-DC converter (for MPPT control) and inverter in it must be replaced by new product which is expected only to consist of inverter. However, the price of conventional power-conditioner is about 5,000 dollars, and it will bring great financial losses if power-conditioner is changed.

Therefore, in order to solve the mismatch problem and reduce financial losses to the minimum, the most ideal way is to add a DC-DC converter behind each module without changing the conventional power-conditioner [4]. The Buck converter is adopted as DC-DC converter. In this paper, simulations of PSIM (power simulation) and experiments are taken to prove this theory. The result shows that, by adding Buck converter for MPPT control to each module, the generated power of the conventional PV generation system can be greatly increased under the condition of mismatch. 


\section{The Problem of the Conventional System}

The conventional system's structure is shown as Fig.

1. It consists of PV array and power-conditioner.

The $\mathrm{P} \& \mathrm{O}$ method (perturbation and observation method) is the most widely used as MPPT control. It is executed by periodically perturbing (incrementing or decrementing) the array terminal voltage and comparing the $\mathrm{PV}$ output power with that of the previous perturbation cycle. If the power is increasing, the perturbation will continue in the same direction in the next cycle, otherwise, the perturbation direction will be reversed [5-8]. The flowchart of this method is represented in Fig. 2.

However, when the PV array is mismatched (for example, one module has a partial shadow), the PV characteristics of the entire array will change from one peak into two peaks (A and B) as shown in Fig. 3. Because of the series connection, when one module is partially shaded, the output current of the entire array will be forced to be decreased. It will lead to a low power output which is peak B in Fig. 3. However, because the bypass diode in modules operates, the module with partial shadow can be bypassed and other modules are able to generate the MPP power (Peak A in Fig. 3).

However, the $\mathrm{P} \& \mathrm{O}$ method will drive the operating point towards the peak $\mathrm{B}$ which has low power output instead of the MPP (A).

\section{The Improved System}

This paper proposed the method which executes the MPPT control to each PV module respectively without changing the conventional power-conditioner.

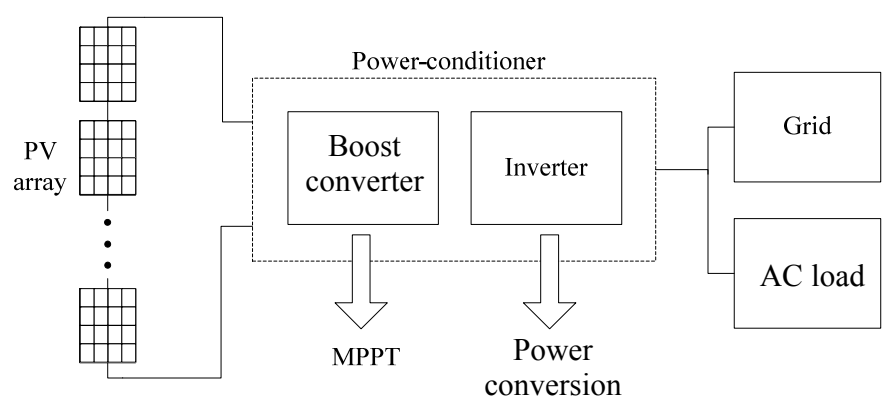

Fig. 1 The conventional PV generation system.

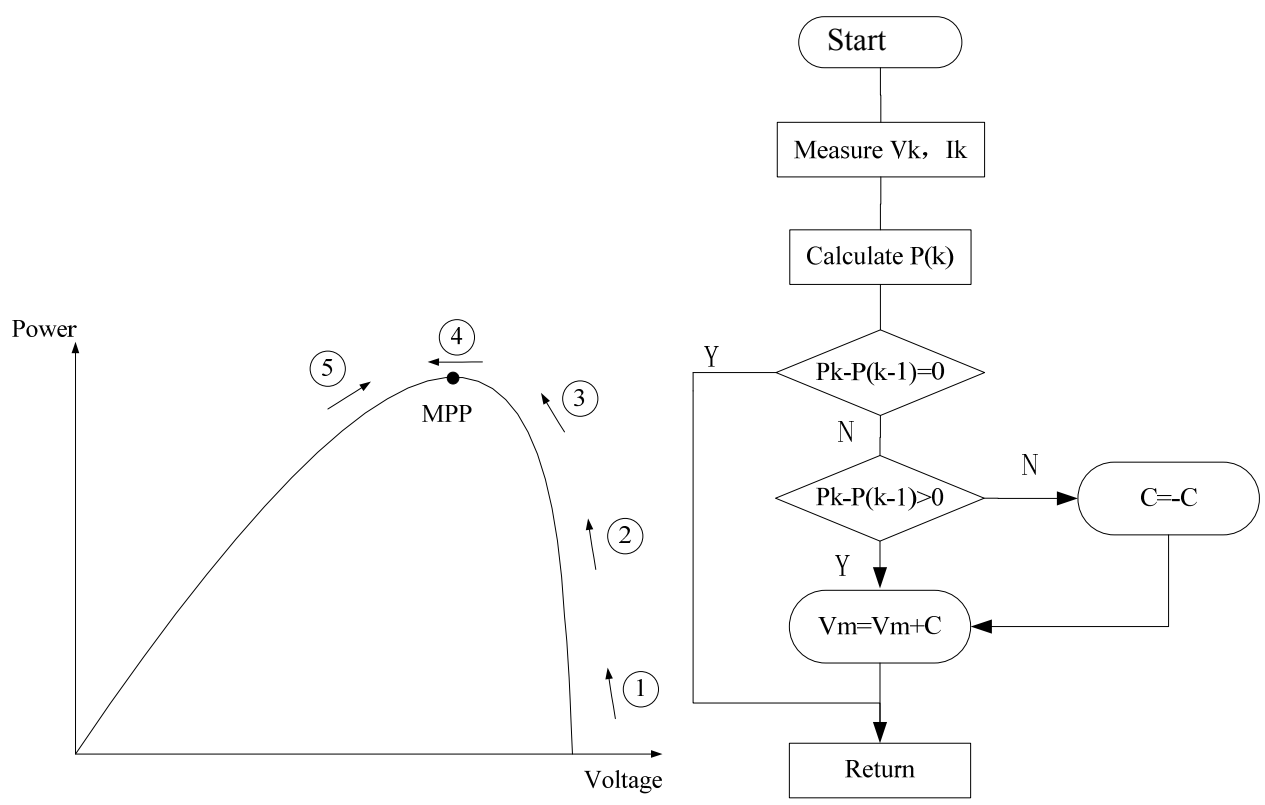

Fig. 2 The flowchart of $P$ \& $O$ method. 


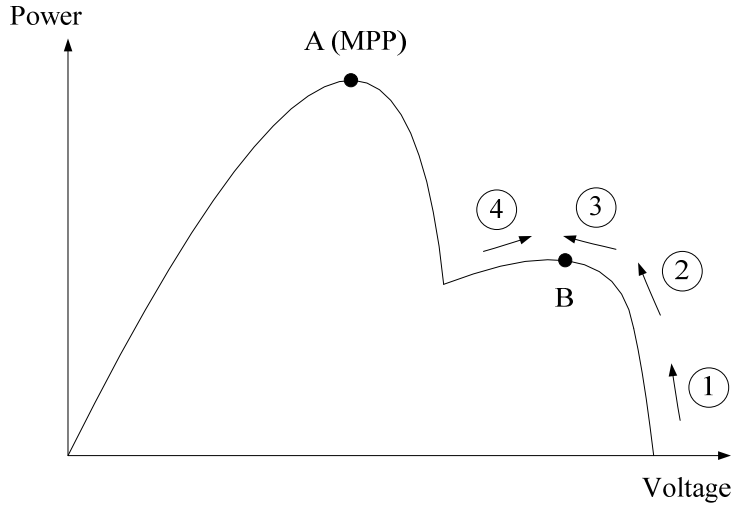

Fig. 3 The operating point when mismatch happened.

As shown in Fig. 4, the improved system consists of PV modules, power-conditioner and the added Buck converters executing MPPT control to each PV module respectively.

Also taking "one module has a partial shadow" as the mismatch condition, with executing MPPT control respectively, the normal modules will not receive the bad effect of mismatch and operate at
MPP as shown in Fig. 5a, while the module with a partial shadow will has a internal mismatch problem as shown in Fig. 5b. In this condition, the total generated power of the improved system will be not only higher than the B in Fig. 3, but also higher than the MPP (A in Fig. 3) of the conventional system when mismatch happened.

\section{Simulation}

As shown in Figs. 6 and 7, in order to prove the theory, the conventional system and the improved system are simulated by PSIM software. The situation of "partial shadow" is taken as the condition of mismatch. In order to verify the theory through experiments, the simulation is made based on the actual parameters.

\subsection{The Simulation of PV Modules}

In order to simplify the system, two pieces of PV modules are set in the simulation, one PV module is

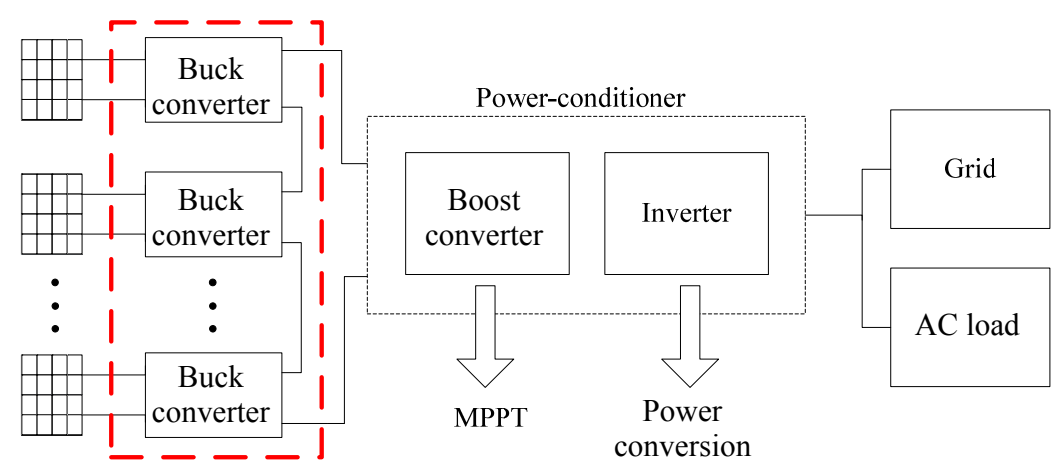

Fig. 4 The improved PV generation system.

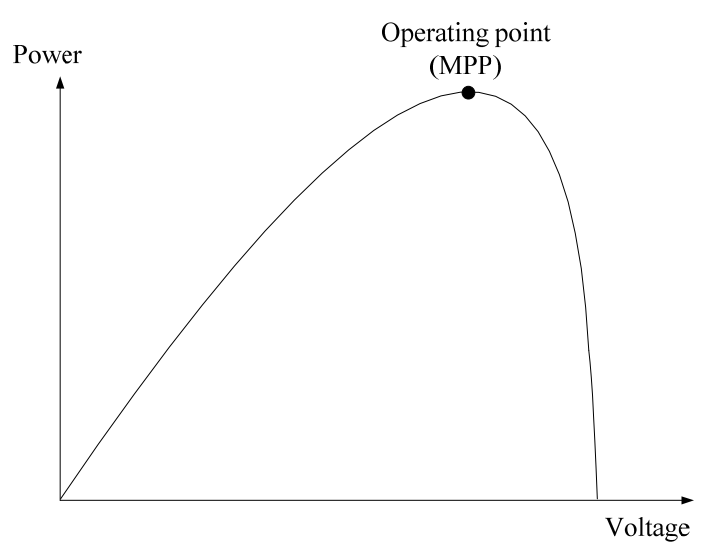

(a) Normal modules

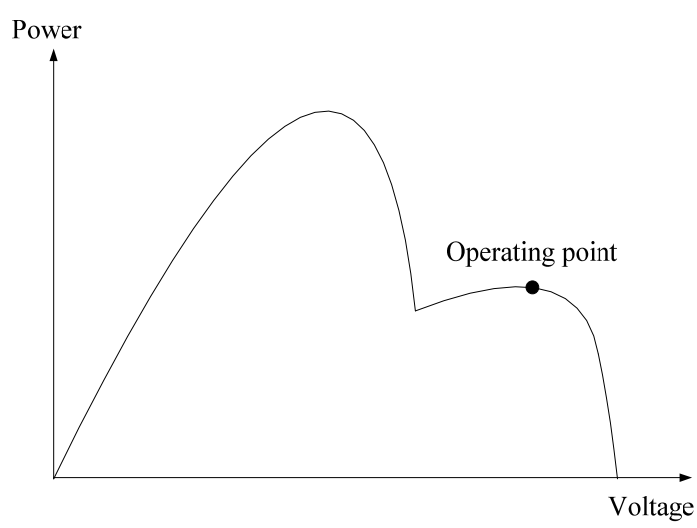

(b) Module with shadow

Fig. 5 The operating point of each module. 


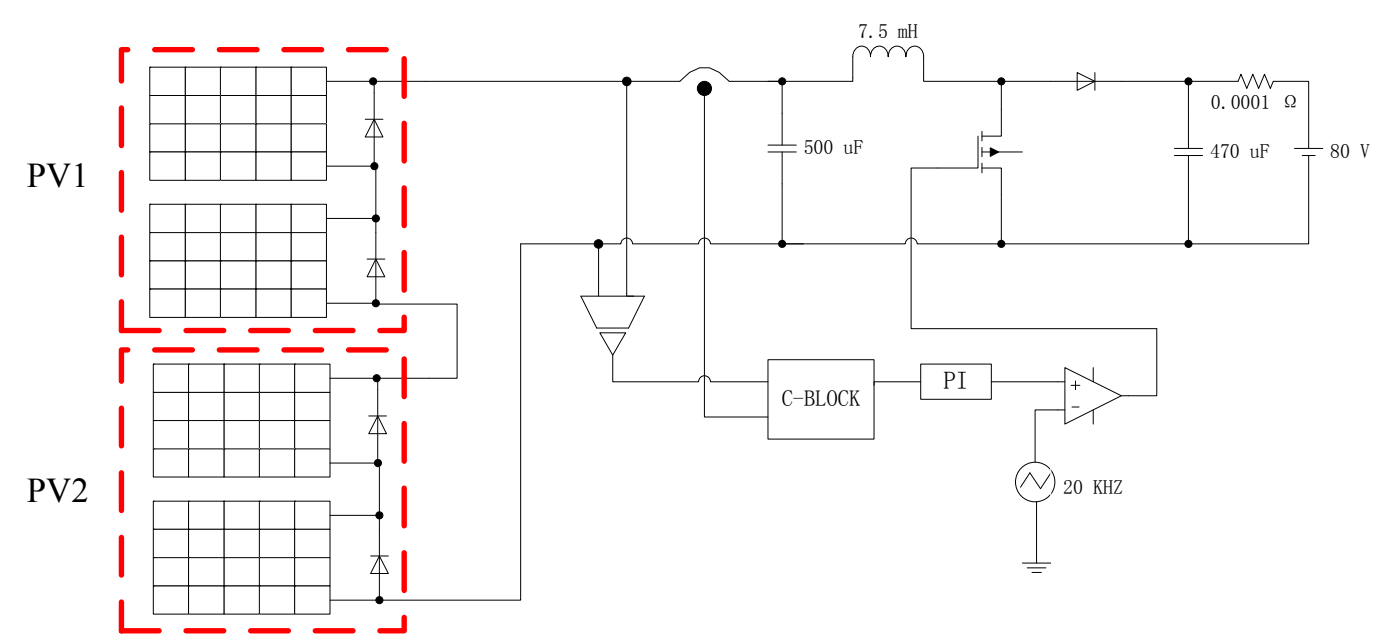

Fig. 6 The simulation of conventional system.

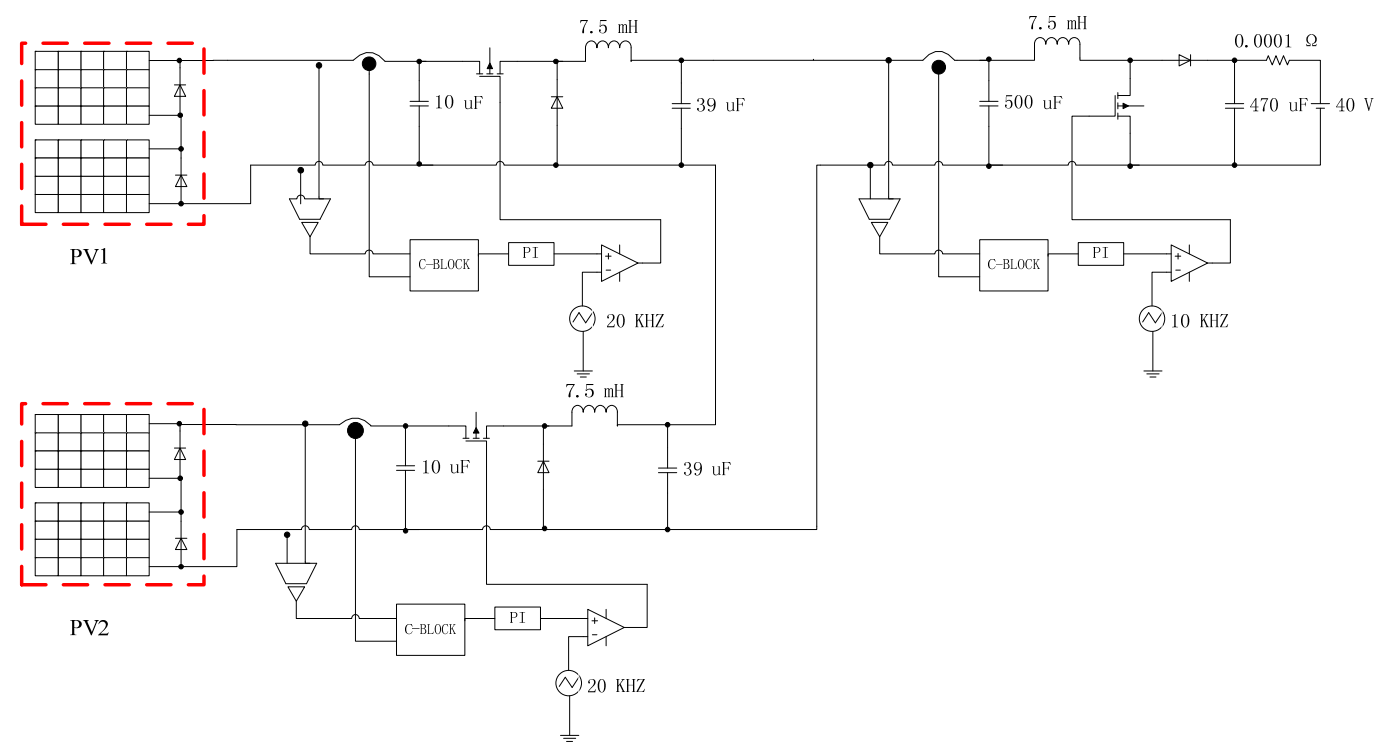

Fig. 7 The simulation of improved system.

supposed to be covered by shadow. The type of PV modules used in the experiment is GT133S manufactured by KIS (Kindness Intelligence Solar Service). This PV module has two clusters of solar cells which are connected in series. Each cluster has a bypass diode. In order to make the simulation close to the real one, PV module is simulated based on the actual parameters by the model of "Solar Module (functional model)" in PSIM.

The simulation of PV module is shown in Fig. 8. Two clusters of solar cells are simulated by two models of "Solar Module" which parallel connected with a bypass diode respectively. The two models are connected in series. As shown in the Table 1, in order to make the models match with the electrical characteristics of the module, voltage parameters of each model is set to half while the current parameters keep the same because of the series connecting.

When one of the solar cells in PV module is partly covered by shadow, the output current of this cluster will be reduced proportionally, and the output voltage will stay the same. So, according to this characteristic, for simulating the PV module which is covered by shadow, one of the "Solar Module" models, the current parameter should be decreased. It is set to one quarter of the original in the simulation: Ipm $=0.7625 \mathrm{~A}$. 

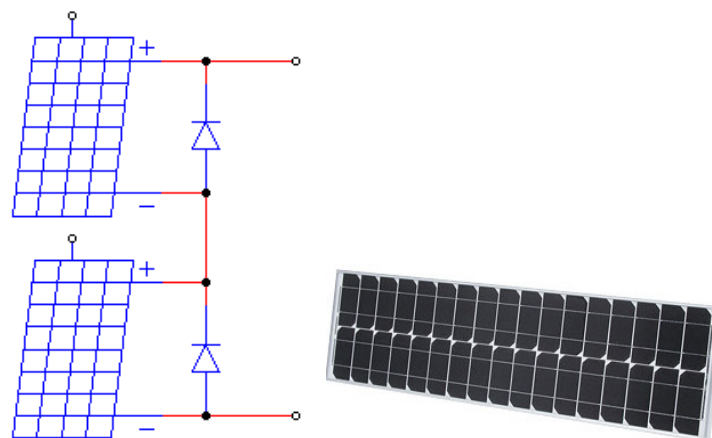

Fig. 8 The simulation of the PV module.

Table 1 Parameters of each "solar module" model.

\begin{tabular}{llll}
\hline & $P m$ & $V p m$ & $I p m$ \\
\hline PV modules (GT133S) & $50 \mathrm{~W}$ & $16.4 \mathrm{~V}$ & $3.05 \mathrm{~A}$ \\
Model (normal) & $25 \mathrm{~W}$ & $8.2 \mathrm{~V}$ & $3.05 \mathrm{~A}$ \\
Model (with shadow) & $6.25 \mathrm{~W}$ & $8.2 \mathrm{~V}$ & $0.7625 \mathrm{~A}$ \\
\hline
\end{tabular}

\subsection{The Simulation of Power-Conditioner}

As shown in Fig. 9, the model of power-conditioner primarily consists of a Boost converter and a battery. The battery can be regarded as an inverter because the input of the inverter is usually controlled at a constant voltage. The MPP is tracked by $\mathrm{P} \& \mathrm{O}$ method in "C-BLOCK".

\subsection{Results of Simulation}

As shown in Figs. 10 and 11, without considering the efficiency of added Buck converters, the average power generation of conventional system is $30.4 \mathrm{~W}$. In the improved system, the average output powers of two PV modules are $49.9 \mathrm{~W}$ and $14.1 \mathrm{~W}$, so the total power generation is $64.0 \mathrm{~W}$. It is raised to $110.5 \%$ as compared with conventional system. Therefore, the simulation proved that, the generated power of the system can be improved under the condition of mismatch by adding Buck converters.

\section{Experiments}

Based on the simulation results, the experiment is taken.

\subsection{Methods of the Experiment}

The picture of PV modules which are taken in the experiments is shown in Fig. 12. In order to make a comparison, four pieces of modules, which have the same electrical characteristics, are divided into two groups. The electrical characteristics of modules are shown in Table 1. One module from each group is covered by a board of the same size to realize the situation of mismatch. The covered area is three quarters of one solar cell.

The experiments are divided into two groups. Group 1 is made based on the structure of conventional household PV generation system. It consists of two modules, a Boost converter and an electronic load (constant-voltage mode). The Boost converter and the

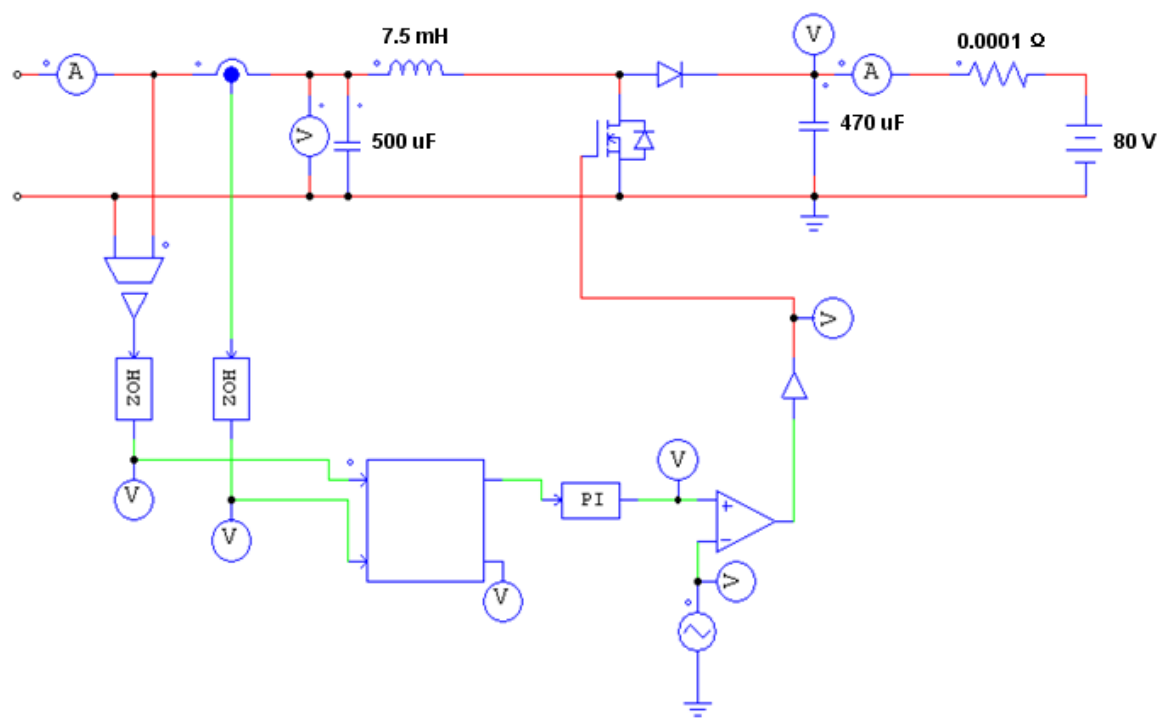

Fig. 9 The simulation of power-conditioner. 


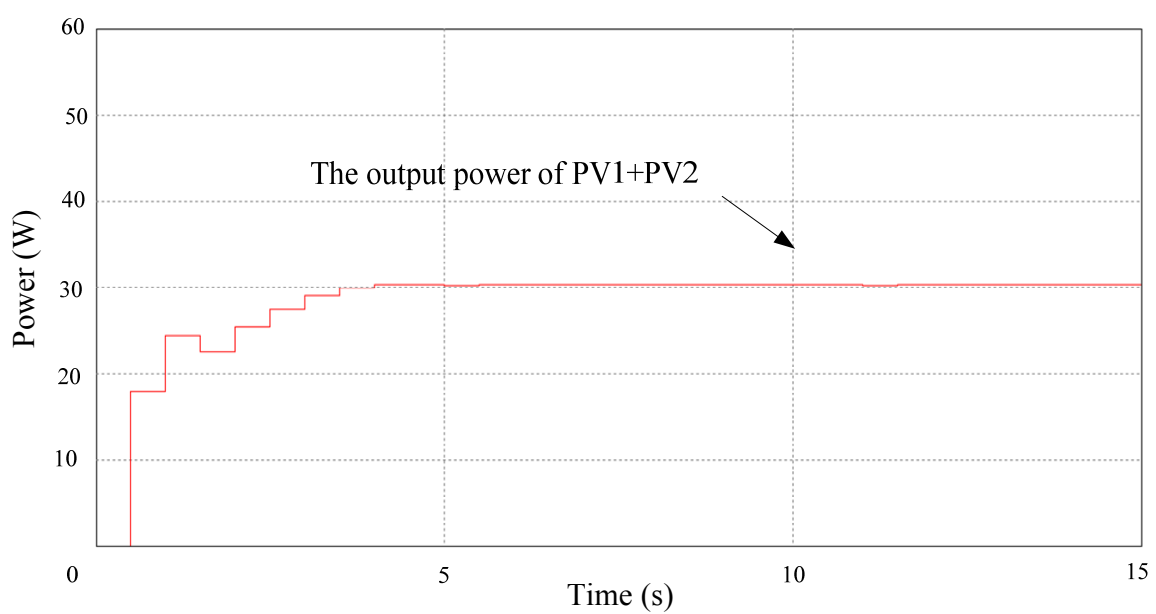

Fig. 10 The result of conventional system.

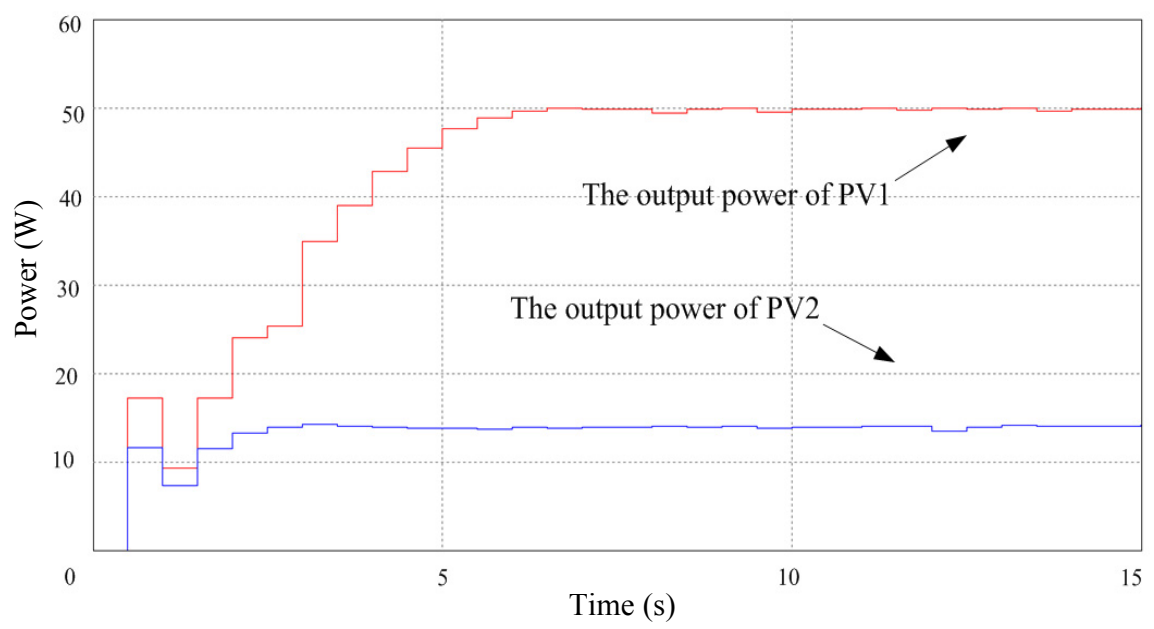

Fig. 11 The result of improved system.

electronic load which are connected in series, function as the power-conditioner. Group 2 implements the scheme of the improved system. It consists of two modules which are connected with a Buck converter (for MPPT control), a Boost converter and an electronic load (power-conditioner), respectively. All the parameters, system structures and control methods are the same with the simulation. The generated power of two groups will be measured and a comparison will be taken.

\subsection{Results of the Experiment}

The date of the experiment is February 21, 2014. The results of Group 1 are shown in Fig. 13.

The results of Group 2 are shown in Fig. 14.

The system condition that, the power loss of the

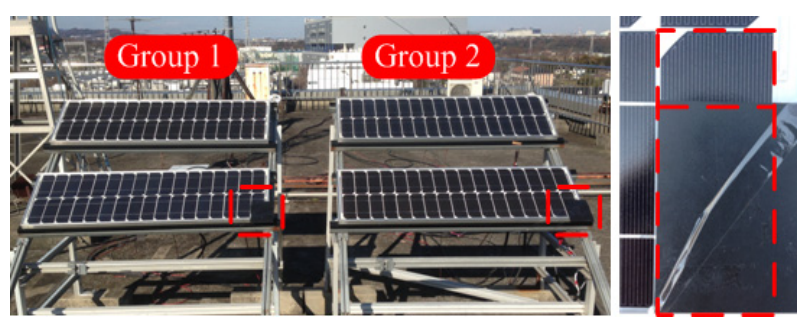

Fig. 12 Two groups of PV modules.

added Buck converters is close to or even greater than the increased generated power, must be avoided. In other words, the efficiency of Buck converters must be confirmed.

In Fig. 15, the average of the input power (Buck $1+$ Buck 2) is $59.5 \mathrm{~W}$, while the average of the output power (Buck 1+ Buck 2) is $52.1 \mathrm{~W}$, so, the total efficiency of two Buck converters is $87.6 \%$.

Fig. 16 shows the total power generation of two 


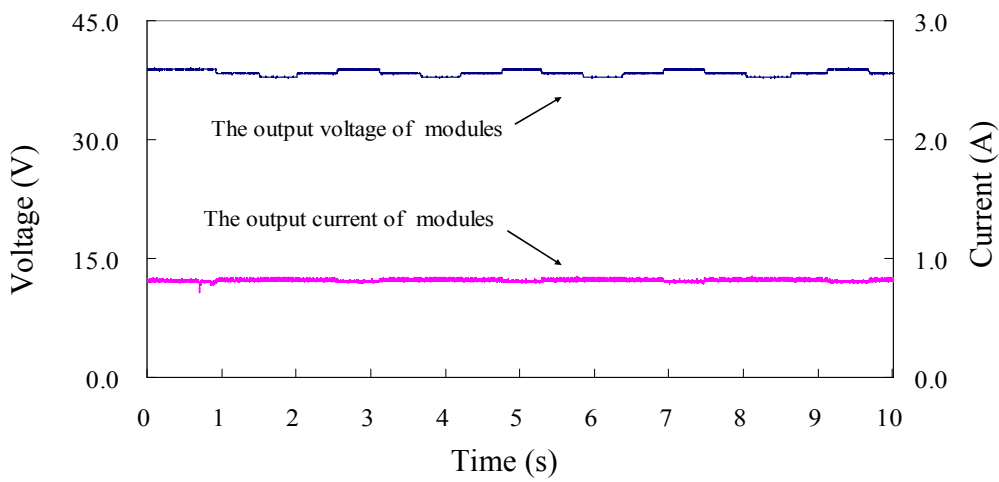

Fig. 13 The output of modules in Group 1.

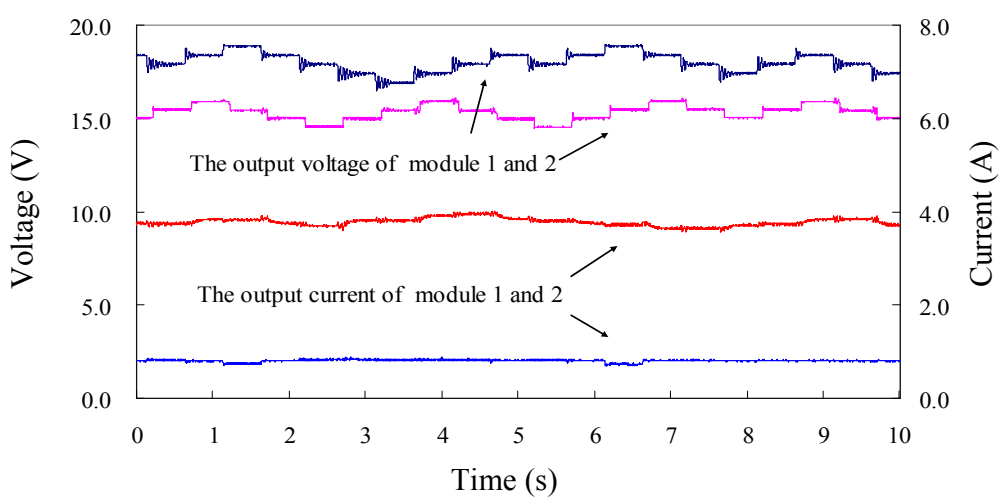

Fig. 14 The output of modules in Group 2.

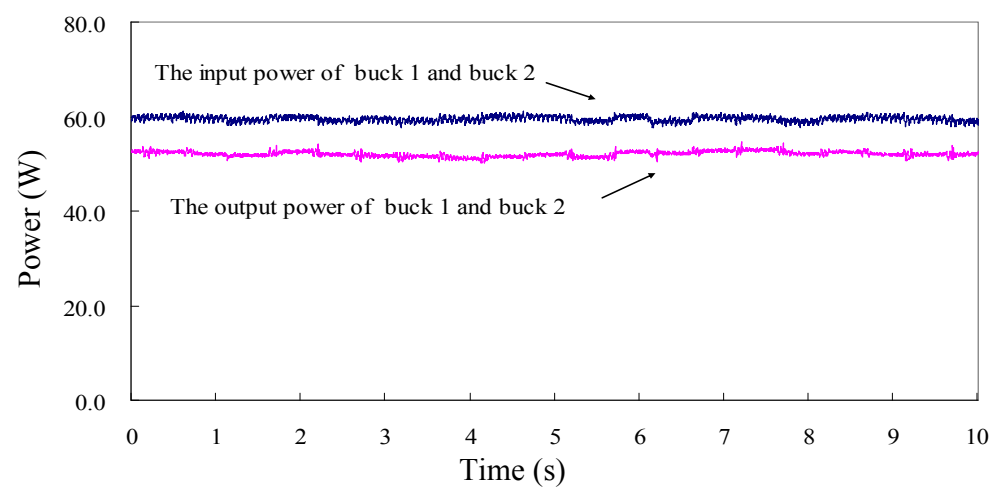

Fig. 15 The input and output power of added Buck converters in Group 2.

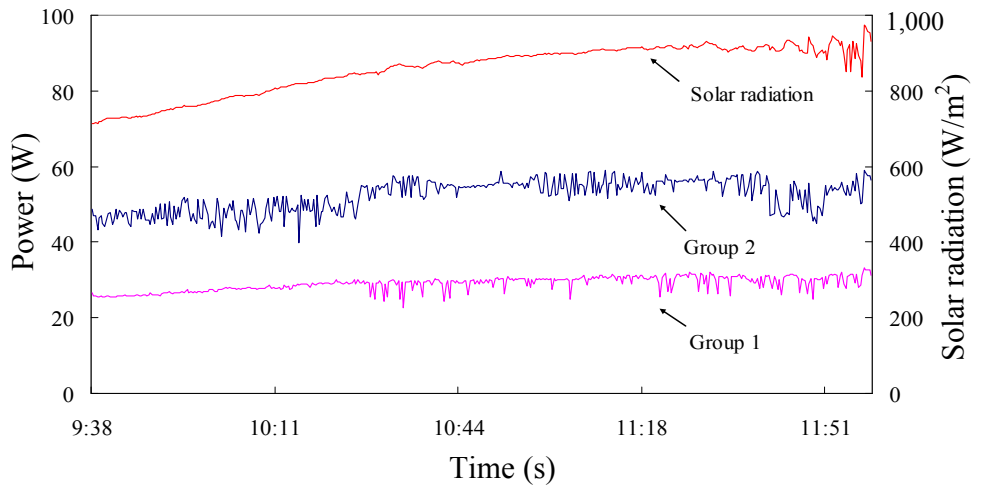

Fig. 16 Total power generation of a day. 
groups in 2.5 hours. The total power generation of Group 1 (the conventional system) is $68.71 \mathrm{Wh}$ while Group 2 (the improved system) is $123.73 \mathrm{Wh}$ (including the power loss of added Buck converters). The power generation of Group 2 is raised to $80.1 \%$ as compared with Group 1 (take $87.6 \%$ as Buck converters' efficiency, $107.01 \%$ raised if the power loss is not included). So it is proved that the idea of adding Buck converters can actually improve generated power of the system under the condition of mismatch.

\section{Conclusion}

This paper proposes the idea that solving the mismatch problem of conventional household PV generation system without changing the conventional power-conditioner. In PSIM simulation and experiments, it is proved that, by adding a Buck converter behind each module respectively, the generated power of the conventional system can be greatly increased under the condition of mismatch.

\section{References}

[1] Sanz, A., Vidaurrazaga, I., Pereda, A., Alonso, R., Roman, E., and Martinez, V. 2011. "Centralized VS Distributed (Power Optimizer) PV System Architecture Field Test Results under Mismatched Operating Conditions." In Proceedings of 2011 the 37th IEEE Photovoltaic
Specialists Conference, 2435-40.

[2] Qiu, Y. N., Betts, T. R., and Gottschalg, R. 2009. "Electrical Mismatch within Single Junction Amorphous Silicon and Micromorph Tandem Thin Film PV Modules." In Proceedings of 2009 the 34th IEEE Photovoltaic Specialists Conference, 911-6.

[3] Paul, P., Ghosh, S. K., Ghosh, K., and Mukherjee, D. 2011. "Impact of Mismatch Losses Arising in Crystalline and Amorphous Silicon PV Modules an Indian Experience.” In Proceedings of 2011 World Congress on Sustainable Technologies, 153-5.

[4] Huang, C. Y., Itako, K., Mori, T., and Ge, Q. 2014. "MPPT Control Method Using Boost Type DC-DC Converter for PV Generation System with Mismatched Modules." Presented at 2014 International Conference on Power Engineering, Energy and Electrical Drives, Singapore.

[5] Subudhi, B., and Pradhan, R. 2012. "A Comparative Study on Maximum Power Point Tracking Techniques for Photovoltaic Power Systems." IEEE Transactions on Sustainable Energy 4 (1): 89-98.

[6] Hua, C. C., Lin, J. R., and Shen, C. M. 1998. "Implementation of a DSP-Controlled Photovoltaic System with Peak Power Tracking." IEEE Transactions on Industrial Electronics 45 (1): 99-107.

[7] Koutroulis, E., Kalaitzakis, K., and Voulgaris, N. C. 2001. "Development of a Microcontroller-Based Photovoltaic Maximum Power Point Tracking Control System." IEEE Transactions on Power Electronics 16 (1): 46-54.

[8] Femia, N., Petrone, G., Spagnuolo, G., and Vitelli, M. 2005. "Optimization of Perturb and Observe Maximum Power Point Tracking Method." IEEE Transactions on Power Electronics 20 (4): 963-73. 